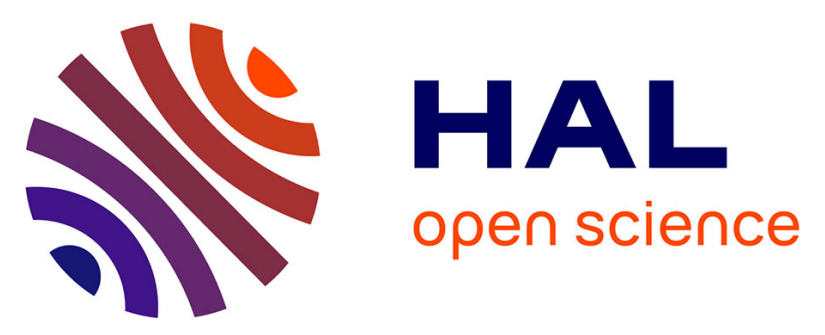

\title{
IN VIVO IDENTIFICATION OF THE PASSIVE MECHANICAL PROPERTIES OF DEEP SOFT TISSUES IN THE HUMAN LEG
}

Fanny Frauziols, Fanette Chassagne, Pierre Badel, Laurent Navarro, Jérôme

Molimard, Nicolas Curt, Stéphane Avril

\section{To cite this version:}

Fanny Frauziols, Fanette Chassagne, Pierre Badel, Laurent Navarro, Jérôme Molimard, et al.. IN VIVO IDENTIFICATION OF THE PASSIVE MECHANICAL PROPERTIES OF DEEP SOFT TISSUES IN THE HUMAN LEG. Strain, 2016, Advances in experimental mechanics for biomedical soft tissues and materials, 52 (5), pp.400-411. 10.1111/str.12204 . hal-01380253

\section{HAL Id: hal-01380253 https://hal.science/hal-01380253}

Submitted on 12 Oct 2016

HAL is a multi-disciplinary open access archive for the deposit and dissemination of scientific research documents, whether they are published or not. The documents may come from teaching and research institutions in France or abroad, or from public or private research centers.
L'archive ouverte pluridisciplinaire HAL, est destinée au dépôt et à la diffusion de documents scientifiques de niveau recherche, publiés ou non, émanant des établissements d'enseignement et de recherche français ou étrangers, des laboratoires publics ou privés. 
1 IN VIVO IDENTIFICATION OF THE PASSIVE MECHANICAL 2 PROPERTIES OF DEEP SOFT TISSUES IN THE HUMAN LEG

3

4 Fanny Frauziols ${ }^{* \circ}$, Fanette Chassagne ${ }^{\star \circ+}$, Pierre Badel ${ }^{\star \circ}$, Laurent Navarro ${ }^{\star \circ}$, Jérôme 5 Molimard $^{\star \circ}$, Nicolas Curt ${ }^{\star \circ}$, Stéphane Avril ${ }^{\star \circ}$

6

7 8

9

10

11

12

13

14 Corresponding author:

15 Name: Fanette Chassagne

16 Address: CIS-EMSE, 158 cours Fauriel, F42023, Saint-Etienne, France

17 Phone : 0477420075

18 Mail : fanette.chassagne@emse.fr

20 


\section{ABSTRACT}

4 Goal: A non-invasive method is proposed to identify in vivo the passive mechanical

5 properties of deep soft tissues in the human leg.

6 How: Force-displacement curves in response to a localized compression of the calf are

7 measured with a custom made experimental setup. The material parameters of a finite

8 element model are then calibrated against the experimental curves using a genetic

9 algorithm. A thorough investigation of the efficacy of this method to identify such

10 mechanical properties is conducted through a design of experiments analysis and mixed

11 numerical - experimental validations.

12 Results: It is the first time that a thorough analysis is conducted to really separate the 13 contribution of deep and superficial tissues in the response to compression tests and 14 this permits to estimate the parameters of deep soft tissues on four subjects 15 independently of the response of their other tissues. Two strain energy density functions 16 are compared. It is shown that a $2^{\text {nd }}$ order reduced polynomial better describes the 17 passive mechanical behavior of the deep soft tissues of the leg than the neo-Hookean 18 model.

19

20 KEYWORDS

21 Calf, Finite element model, Inverse method, Soft tissues

22

23

\section{ACKNOWLEDGEMENTS}

24 The authors are grateful to the C.N.R.S. (French Scientific National Research Center) 25 for funding the Ph.D. grant of F.F. The authors thank Liliane Chassin de Kergommeaux 26 for her technical support.

27

28 


\section{INTRODUCTION}

\section{1. Motivations}

3 Different draining mechanisms prevent blood from stagnating in the legs of healthy 4 subjects, such as the effect of muscular contraction, the activity of the sympathetic nervous system or the venous valve system [1]. In case of default in one of these mechanisms, chronic venous insufficiency $(\mathrm{CVI})$ may appear. Symptoms of $\mathrm{CVI}$ range from "heavy leg" feelings to development of ulcers. CVI affects about thirty percent of the French population [2]. Compression of the limb using medical compression stockings or bandages is a widely used treatment and is efficient for almost all forms of CVI [3]. The benefits of these treatments are not to be proven, but still, for some patients, the therapeutic goal is not reached and generally, there is a need to improve their comfort. To understand the mechanisms of this treatment and to be able to better design and size the stockings or bandages, biomechanical numerical models have been developed 14 [4]-[7].

A challenging step to develop these models is to identify the material properties of soft tissues. To that extent, several characterization methods have been established. A first approach to characterize the mechanical properties of soft tissues is to perform in vitro tensile or compression tests on tissue sample [8], [9]. A second and more recent approach is by direct measurements of the mechanical properties of soft tissues in vivo with different techniques. For example, ultrasound elastography [10] and magnetic resonance elastography [11] techniques both map the elasticity of soft tissues. A third approach is to combine experimental data acquisitions with finite element (FE) model updating through an inverse method. This approach can address experimental data that could not be analyzed directly to identify material parameters of different constitutive models. Previously, FE model updating has been used in vivo on arterial tissue [12], brain tissue [13], skin [14] and adipose tissues [15] or musculo-skeletal tissues [4], [5], [16],[17].

\section{Problem definition and proposed approach}

The leg is composed of several compartments made of soft tissues (Figure 1): - the compartment composed of adipose tissue and skin which, in this study, is

It is believed that the transmission of pressure through soft tissues plays an important role in the treatment of venous insufficiency by elastic compression [4]. Therefore, 40

modelling

1
2
3
4
5
6
7
8
9
10
11
12
13
14
15
16
17
18
19
20
21
22
23
24
25
26
27
28
29
30
31
32
33
34
35
36
37
38
39
40 referred to as superficial soft tissues;
- the Fascia cruris which is a collagenous membrane separating both compartments;
- the compartment of soft tissues surrounded by the fascia cruris, mainly composed of muscular tissue which, in this study, is referred to as deep soft tissue compartment.


1 identification of the constitutive behavior of this medium through which the pressure is 2 transmitted.

3 Also, a large inter-subject variability in the efficacy of the compressive treatments has 4 been observed previously [18]. Therefore, the identification of mechanical properties 5 must be patient-specific.

6 Thus, a non-invasive and fast methodology is required to permit further clinical studies 7 with large cohorts.

9 In this context, a fast and non-invasive method to identify passive mechanical properties

10 of deep soft tissues is proposed and evaluated. Using an inverse method, subject11 specific FE models and experimental localized compression data sets are combined to 12 identify material parameters on four healthy subjects. The related assumptions are 13 discussed to assess the accuracy of this approach.

\section{General outline of the paper}

16 The material and methods section details the methodology used to retrieve subject17 specific material properties by acquiring localized compression data on the leg and 18 implementing an inverse method. Then, in the results section, accuracy of the 19 methodology is assessed and the material parameters of each subject are reported. 20 Finally, in the discussion section, the experimental set-up and the assumptions of the FE 21 model are thoroughly discussed to present their domain of validity and limitations. 


\section{MATERIAL AND METHODS}

\section{Data acquisition and processing}

3 Four volunteers (3 males, 1 female, mean age: 27) underwent MRI scans, ultrasound acquisitions and localized compression data acquisition on the calf of the right hand-side of the leg, following informed consent. The ultrasound acquisitions (Figure 2 - A) and the MRI scans (Figure 2 - B) provide the subject-specific geometry used for the implementation of a FE model (Figure 2 - C). An ultrasound elastographic device (Aixplorer ${ }^{\circledR}$; Super-Sonic Imagine, Aix-en-Provence, France) was used in a previous study [19] to reconstruct the fields of elastic modulus in the superficial tissues. B-mode scans acquired all around the leg were stitched together to reconstruct the anatomy of superficial soft tissues of the subject.

In the present study, an experimental setup has been designed to identify the passive mechanical properties of deep soft tissues. More specifically, displacements and reaction forces were measured after compressing the calf with a $30 \mathrm{~mm}$ diameter cylinder (Figure 3). Since these experimental data were aimed at being combined to a bi-dimensional finite-element (FE) model, a cylinder was chosen rather than a sphere. More, it is worth noting that with such geometrical arrangement, material with linear elastic behavior would give a linear force/displacement curve..

20 During data acquisition, the subject was seated in a chair allowing a relaxed state of the calf muscles. The subject's foot was fixed with straps and the knee was supported by rubber buffers avoiding motions of the leg during the acquisition. Double-sided adhesive tape was used at the leg-cylinder contact in order to avoid sliding. This adaptation reduces the number of unknowns in the inverse approach (i.e. no friction coefficient to identify), lowering the computation time.

25 An in-house LabVIEW ${ }^{\circledR}$ (National Instruments, Austin, TX, USA) code was used to display and record the reaction forces given by the $100 \mathrm{~N}$ load cell (LCMKD-100N, Omega engineering INC) with an accuracy of $\pm 0.25 \%$ and the displacements given by the $50 \mathrm{~mm}$ displacement sensor (MTN/EUG025-10, Monitran) with an accuracy of \pm 0.25 $\mathrm{mm}$. Three sets of localized compression were acquired per subject at a rate of 0.4 $\mathrm{mm} / \mathrm{s}$. The compression was increased until a displacement of $30 \mathrm{~mm}$ of the cylinder was reached. Only the loading part of the curve was further analyzed for the inverse analysis. This choice will be commented in the discussion section.

\section{Implementation of a subject-specific FE model}

37

38

The aim of the paper is to identify the deep soft tissue material parameters using an

39 inverse FE analysis through an iterative process. Two imaging modalities were used to create the subject-specific FE model: ultrasound (Figure 2 - A) and MRI (Figure 2 - B). To register both images, the bones edges visible in both images were segmented and 
used to perform a rigid body registration. The external geometry of the leg was 2 segmented from the ultrasound images [20] as well as the position of the fascia cruris.

3 Since the thickness of the fascia cruris shows high inter-individual variability [21] and 4 cannot be precisely determined from ultrasound images, a sensitivity analysis was 5 performed about this parameter.

In a first model, the behavior of soft tissues was described with a neo-Hookean hyper-

8 elastic constitutive equation. The strain energy density function was defined such as 9 [22]:

$10 U=C_{10}^{H}\left(\bar{I}_{1}-3\right)+\frac{1}{D_{1}}\left(J^{e l}-1\right)^{2}$

Equation 1

12 where $\bar{I}_{1}$ is the first invariant of the isochoric deformation; $J^{e l}$ the elastic volume ratio; $C_{10}^{H}$ 13 and $D_{1}$ the material parameters to identify.

14

In a second model, the behavior of deep soft tissues (i.e. below the fascia cruris) was modelled with a $2^{\text {nd }}$ order reduced polynomial strain energy density function defined such as [22]:

$$
\begin{array}{rr}
U=\mathrm{C}_{10}^{P}\left(\bar{I}_{1}-3\right)+C_{20}\left(\bar{I}_{1}-3\right)^{2} & 18 \\
+\frac{1}{D_{1}}\left(J^{e l}-1\right)^{2}+\frac{1}{D_{2}}\left(J^{e l}-1\right)^{4}
\end{array}
$$

Equation 2

20 where $C_{10}^{P}, C_{20}, D_{1}$ and $D_{2}$ are the material parameters to identify.

Material parameters are summarized in Table 1. $D_{1}$ and $D_{2}$ were not identified in this study, common values were assigned to them [16]. This choice is discussed in the 24 discussion section.

25

The iterative process to identify the material parameters requires a low computation time of the FE simulation. This is why it was chosen, in accordance with previous studies [4], [6], [16], to implement a bi-dimensional FE model to mimic the 3D experiments. The construction of the bi-dimensional FE model whose purpose is to replicate the $3 \mathrm{D}$ experiment required several assumptions. Considering the chosen geometrical arrangement, the bi-dimensional FE model is based on a classical plane-strain model combined with correction functions in order to take into account the 3D effects.

As the soft tissues compression test was performed thanks to a $50 \mathrm{~mm}$ long cylinder, 36 B ). edge effects may occur due to a non-uniform pressure distribution on the leg (Figure 4 -

37 In order to assess the influence of the change from a 3D experiment to a plane-strain FE 38 model, a 3D model representing the experimental 3D problem was implemented and 39 compared to a plane-strain model. Idealized leg geometry was used to create the 3D FE 40 mesh, made of first order tetrahedral elements, using the meshing tools available in 
Abaqus $^{\circledR}$. The material behavior was described by a neo-Hookean constitutive equation (Equation 1).

3 Two computations were performed. In the first one, named 3D simulation, the compression of the idealized leg is modelled in 3D with a $30 \mathrm{~mm}$ diameter and $50 \mathrm{~mm}$ long cylinder (Figure $4-A-1$ ). The external surface of the idealized bone was pinned and the top and bottom faces of the idealized leg segment were unconstrained. In the second one, named plane-strain simulation, the compression of the idealized leg is modelled in plane strain with a $30 \mathrm{~mm}$ diameter circle (Figure $4-\mathrm{A}-2$ ). Plane-strain results being calculated for a unit transverse length, reaction forces were multiplied by the length of the compression cylinder (i.e. $50 \mathrm{~mm}$ ). In order to evaluate the error due to edge effects (Figure $4-\mathrm{B}$ ) made with a plane strain FE model, a correction function, $\mathrm{P}$,

13 computations as follows:

$$
P(d)=1-\frac{\frac{R F^{3 D}(d)}{L^{c y l i n d e r}}}{R F^{2 D}(d)} \quad 14
$$

Equation 3

16 with, $R F^{3 D}(d)$ and $R F^{2 D}(d)$ being the reaction forces obtained respectively from the 3D

17 and $2 \mathrm{D}$ simulations, as a function of the displacement of the cylinder $d, L^{\text {cylinder }}$, the

18 length of the cylinder. The results were used to apply a correction function (Figure $4-C$ ) on the force/displacement curves in the bi-dimensional FE models for the 4 subjects.

Eventually, the bi-dimensional reconstruction comprising the bones, the compartment of superficial soft tissues and the compartment of deep soft tissues, separated by the fascia cruris (Figure 2 - C) was meshed with 3-node and 4-node linear plane strain finite elements with hybrid formulation, using the meshing tools available in Abaqus ${ }^{\circledR}$.

The compression cylinder was modelled as a $30 \mathrm{~mm}$ diameter circle (Figure $2-\mathrm{C}$ ). Its initial position and its translation direction were defined in agreement with each experiment. The two bones and the cylinder were implemented as rigid bodies. The bones were pinned and a $30 \mathrm{~mm}$ radial displacement was assigned as boundary condition of the FE model for the cylinder.

In this study, the interaction between the leg and the cylinder was managed using contact algorithms from those available in the Abaqus ${ }^{\circledR}$ library. In the tangential direction, a rough behavior was chosen (i.e. infinite coefficient of friction) to satisfy the 33 experimental conditions (i.e. double-sided adhesive tape at the cylinder/leg interface). In 34 35 36 the normal direction, an exponential contact pressure/over-closure relationship was used.

\section{Evaluation of the FE model sensitivity}

A sensitivity analysis of the FE model response to parameters of interest has been performed for one subject through a design of experiments approach [23]. This methodology allowed determining the sensitivity of the FE model to each parameter 
(material parameters or thickness of the fascia cruris for example) and defining whether 2 this bi-dimensional FE model can be used to identify the material parameters of deep soft tissues. For this sensitivity analysis, the behavior of deep soft tissues was modelled with a $2^{\text {nd }}$ order reduced polynomial strain energy density function (Equation 2), as it was observed that this constitutive law better fits the experimental results.

\section{Parameter selection}

85 parameters were taken into consideration, the $C_{10}^{P}$ and $C_{20}$ material parameters of deep soft tissues, the thickness of the fascia cruris, the $C_{10}$ material parameter of the fascia cruris and the $C_{10}^{H}$ material parameter of the superficial soft tissues (Figure 1). To compare the sensitivities, the parameters were scaled and centered from - 1 to 1 in their respected domain as reported in Table 2.

\section{Sampling method}

The set of numerical simulations performed was defined using a full factorial design with interactions and resulted in 33 simulations $\left(n=2^{5}+1\right)$.

\section{Selection of metrics from the FE analysis}

Two types of metrics were studied in order to capture the non-linearity of the response. The first one is the mean slope of the force/displacement curve. The second one is the mean curvature of the force/displacement curve. For each metrics, 3 parts of the force/displacement curve were analyzed to study the influence of the parameters at different stages of the compression test: from $0 \mathrm{~mm}$ to $5 \mathrm{~mm}$; from $5 \mathrm{~mm}$ to $20 \mathrm{~mm}$; from $20 \mathrm{~mm}$ to $30 \mathrm{~mm}$ (Figure $5-\mathrm{A}$ ).

\section{Response surface definition}

A response surface was then fitted on the metrics values obtained from the 33 numerical simulations. This surface response was modelled with a first order polynomial (Equation 30

4 ) including interactions ( 5 studied parameters coefficients +10 interaction coefficients + 1 constant term).

$$
Y=\beta_{0}+\sum_{i=1}^{p} \beta_{i} \times x_{i}+\sum_{\substack{i, j=1 \\ j>i}}^{p} \beta_{i j} \times x_{i} \times x_{j 32}^{31}
$$

Equation 4

33

34

35

36

where $p=5$ is the number of parameters; $Y$ is the output of the model and $x$ the parameter value in its coded space. Except for $\beta_{0}$, the absolute value of the coefficients $\beta$ will reflect the sensitivity of the FE model to the corresponding parameters.

\section{Statistical analysis of the response surface}

To assess the quality of the fitted response surface, a statistical analysis was used. After ensuring that the outputs of the 33 simulations followed a Normal law, an analysis of 
1 variance (ANOVA) was performed [23]. The sum of squares due to the error (SSE) and 2 the sum of squares due to the regression (SSR) were calculated as follows:

$$
\begin{aligned}
& S S E=\sum_{i=1}^{n}\left(Y_{i}-\hat{Y}_{i}\right)^{2} \quad 4 \\
& S S R=\sum_{i=1}^{n}\left(\hat{Y}_{i}-\bar{Y}_{i}\right)^{2}
\end{aligned}
$$

7 where $n=33$ is the number of simulations; $Y_{i}$ are the outputs of the simulation; $\bar{Y}_{i}$ are

8 the means of the outputs and $\hat{Y}_{i}$ are the estimated outputs computed from the fitted

9 model.

10

11 From these values the mean sum of squares due to the error (MSE) and the mean sum 12 of squares due to the regression (MSR) were deduced. Then, the linear coefficient of 13 regression was calculated.

$$
\begin{aligned}
& \begin{array}{ll}
M S E=\frac{S S E}{n-p} & 14 \\
15
\end{array} \\
& M S R=\frac{S S R}{p-1} \quad 16 \\
& \begin{array}{ll}
R^{2}=\frac{S S R}{S S T} & 18 \\
& 19
\end{array}
\end{aligned}
$$

20 where $n=33$ is the number of simulations and $p=5$ the number of parameters.

22 The global validity of the model was then assessed by applying a Fisher test with $(p-1)$ 23 and $(n-p)$ degrees of freedom to the following quantity:

24

$$
T^{\text {model }}=\frac{M S R}{M S E}
$$

Equation 10

26 Finally, the significance of the sensitivity of each parameters with respect to the 27 experimental variance, $\hat{\beta}_{i}$, was assessed by applying a Student test with $(n-p)$ degrees 28 of freedom to the quantity:

$$
T^{\text {parameter }}=\frac{\hat{\beta}_{i}}{\sqrt{\operatorname{Var}\left(\beta_{\text {experimental }}\right)}} \quad 29
$$

Equation 11

31 The results of this design of experiments applied to the FE model are presented in the 32 results section.

33

\section{Identification method}

35 To identify the material parameters of both constitutive models $\left(C_{10}^{H}\right.$ for Equation $1 ; C_{10}^{P}$ 36 and $C_{20}$ for Equation 2), an inverse method was implemented.

38 Several steps were necessary: 
1. Extraction of force-displacement curves from the bi-dimensional model.

2 2. Definition of a cost function quantifying the mismatch between numerical and 3 experimental force-displacement curves.

43 3. Minimization of the cost function with the genetic algorithm implemented in $5 \quad$ Matlab $^{\circledR}$.

7 To estimate the mismatch between numerical and experimental force-displacement 8 curves, the reaction forces from the numerical simulations and the experiments were 9 sampled on an identical displacement range and the cost function was defined in the 10 least square sense:

$$
E=\sum_{i=1}^{l}\left(Y_{\text {sim }}(i)-Y_{\text {exp }}(i)\right)^{2} \quad \begin{array}{ll}
11 \\
12 \\
13
\end{array}
$$

\section{Equation 12}

14 where $l$ is the number of points, $Y_{\text {sim }}$, the reaction forces predicted by the numerical 15 simulation and $Y_{\text {exp }}$, the obtained experimental reaction forces.

16

17 The stopping criterion of the genetic algorithm was the tolerance on the cost function, 18 which was set to $10^{-3}$. Reaction forces were of the order of magnitude $1910^{0}$. 


\section{Results}

\section{FE Model sensitivity}

4 A design of experiments approach was used to evaluate the sensitivity of the FE model 5 to different parameters. The aim was to ensure that this simulation can be used to 6 identify deep soft tissue mechanical parameters (i.e. that the response of the simulation 7 is sensitive enough to deep soft tissue mechanical parameters).

\section{Statistical analysis of the response surface}

10 The results of the ANOVA test concerning the surface response evaluation (Equation 5 to Equation 11) are reported in Table 3. The coefficients of determination, $R^{2}$, are above $99 \%$ for all tested metrics except for the mean slope for depth of compression in the 20$30 \mathrm{~mm}$ range. This indicates that the first order surface response (Equation 4) provides a very good agreement with the simulation sets.

\section{Parameters sensitivity}

The $1^{\text {st }}$ order polynomial coefficients (Equation 4) calibrated against the mean curvature values are shown in Figure $5-\mathrm{B}$. They represent the sensitivity of the FE model response to each parameter: the higher the absolute value of the coefficient, the more sensitive the FE model response to a change in this parameter. These coefficients were derived from simulations at 3 different stages of the force/displacement curves. Those adjusted on the mean slope are shown in Figure $5-\mathrm{C}$. Coefficients characterizing the combined effects of the different parameters ( $\beta_{i j}$ - Equation 4$)$ were derived but they are not significant, so they are not reported here.

25

The values of the sum of squares due to the regression are higher for the second and third parts of the force/displacement curves, for all studied metrics. This indicates that the identification of the material parameters of the constitutive equations for deep soft tissues is more relevant as the compression progresses.

30 For both types of analyzed metrics (i.e. mean curvature and mean slope of the force/displacement curves), the sensitivities are significantly higher for the material properties of the deep soft tissues, which means that they have a greater impact on the response.

34 This result confirms that the proposed combination of experimental and numerical 
2 Experimental data

3 For the four subjects, the responses to a $25 \mathrm{~mm}$ deep localized compression with a 30

$4 \mathrm{~mm}$ diameter cylinder were acquired according to the methodology described before.

5 The results are shown in Figure 6.

6

7 Identification: neo-Hookean strain energy density function

8 An example of the experimental and numerical force/displacement curves after 9 identification of the $C_{10}^{H}$ material parameter (Equation 1) is shown in Figure $7-\mathrm{A}$.

10 The results of the identified parameter $C_{10}$ for 4 subjects and the related cost function 11 values are reported in Table 4.

13 Identification: 2 nd order reduced polynomial strain energy density function

14 An example of the experimental and numerical force/displacement curves after 15 identification of $C_{10}^{P}$ and $\mathrm{C}_{20}$ (Equation 2) is shown in 16 Figure $7-\mathrm{B}$.

17 The $\mathrm{C}_{10}$ and $\mathrm{C}_{20}$ values for four subjects and the related cost function values are 18 reported in Table 5.

19 


\section{Discussion}

\section{1. Contribution of the study}

3 The methodology developed in this study is a fast and efficient tool to identify the passive mechanical properties of deep soft tissues in the leg of several subjects, taking into account the non-linear behavior of these tissues. In the literature, only a few noninvasive methods have already been developed to identify the passive mechanical properties of deep soft tissues and it is the first time that a thorough analysis is conducted to really separate the contribution of deep and superficial tissues in the response to compression tests or indentation tests.

A method combining an axisymmetric multi-layer (i.e. skin, adipose tissue) FE model with an indentation experiment was used to identify the mechanical properties of the forearm soft tissues [15]. A small indentor allowed recruiting the behavior of superficial soft tissues only. An interesting point of this technique was to identify separately each type of soft tissues.

Also, the characterization of the soft tissues of the leg has been performed for several subjects [5], [16]. FE models of the leg in a relaxed initial state and a compressed state with stocking were compared to MRI scans of the legs in the same two states. The identification was performed between two loading states and could not capture the nonlinear behavior of soft tissues. However, the FE model was composed of two compartments of soft tissues, allowing a distinction between the mechanical properties of adipose tissue and muscular tissue.

Finally, a study similar to the one presented here identified mechanical properties of soft tissues of the calf [24]. An inverse method combined a subject-specific FE model with the indentation of the leg at the calf location by $8 \mathrm{~mm}$ or $19 \mathrm{~mm}$ diameters cylinders. In this case, the cylinders were applied perpendicularly to the leg axis. Nevertheless, this FE model was composed of only one compartment of soft tissues, without any distinction between skin, fat and muscle.

The leg geometry in the FE model was defined from the ultrasound reconstruction and might differ from the actual leg geometry during the acquisition of the compression data. Indeed, both data sets were not acquired on the same day but also, the leg position differed between both data acquisitions: prone position for the ultrasound image acquisition; sitting position for the compression test.

The effects of these geometrical differences and their impact on the identification of mechanical properties still need to be investigated. This matter could be prevented if the 
tissues, with a 3D optical scanner for example. A 3D scanner will provide the external

2 geometry of the leg, but also the exact location of the cylinder before the compression

3 as well as the direction of the cylinder displacement. Nevertheless, the bones location

4 and the different soft tissue compartments are not available with this imaging modality.

5 As the aim of the study was to identify deep soft tissues mechanical properties, it would

6 have been impossible to use the 3D scanner to implement the simulation, as it only

7 provides the external geometry of the leg.

\section{Numerical assumptions}

The subject-specific FE model of the leg implemented in this study is based on several assumptions discussed here.

\section{Bi-dimensional FE model} The identification process compares the 3D experimental curves with that of the bidimensional FE model. The bi-dimensional FE model is built on a classical plane-strain model combined with correction factors taking into account 3D effects. As a matter of fact, a plane-strain model would be insufficient, the 3D effects corresponding to about $15 \%$ of the reaction force (Figure $4-\mathrm{C}$ ). This reduction of the 3D model may be questionable for small displacements. Indeed, in the first millimeters of the localized compression, the contact length is smaller than the length of the applied cylinder because the leg is not a perfect cylinder. Not surprisingly, the design of experiments showed that the identification of material parameters is more significant for a displacement larger than $5 \mathrm{~mm}$.

\section{Material compressibility}

It is fairly common to assume soft tissues as nearly incompressible in vivo because they are mainly composed of water [8]. However, a preliminary study showed that a fully incompressible strain energy density function raised numerical issues. Consequently, a slightly compressible model was chosen and $D$ values for both constitutive equations (Equation 1 and Equation 2) were selected from a previous study [16]. In the latter study, a difference of leg cross-section area of about $5 \%$ was observed in MRI transverse scans between wearing and not wearing compression stockings (Class II delivering 33 averagely a $20 \mathrm{mmHg}$ pressure to the calf).

34 Two phenomena could explain this observation of tissue loss of volume. First, when the 35 leg is under compression, the venous system is drained compared to the uncompressed 36 state and second, soft tissues can move upwards when a compression stocking is worn. 37 Thus, the loss of area occupied by the leg in the MRI transverse planes could be the 38 combined result of blood draining and $3 \mathrm{D}$ deformations. Assigning the $\mathrm{D}$ values reported 39 in Table 1 was sufficient to take these effects into account in the models. An 
improvement could be to identify a subject-specific compressibility parameter, but this

\section{Viscoelasticity}

The methodology described in this paper presents the identification of soft tissues elastic properties. However, human soft tissues are often considered as viscoelastic materials [25]. The experimental setup was designed to compress soft tissue with a very low displacement rate. It was checked that displacement rate variation (within the range being possible with this setup) had negligible influence on the response. This confirms that for the timescales of the experiments, viscoelastic effects remain negligible and hence an identification on the loading curve is convenient.

\section{Design of experiments}

Several studies raised questions about the mechanical role of the fascia cruris in the biomechanics of elastic compression, one of them being the contention of muscular tissues [26], [27]. However, the sensitivity analysis performed here showed no significant effect of its mechanical properties or of its thickness. It is still possible that the fascia cruris plays a biomechanical role but that this role is marginally involved in the localized compression applied here. Other investigations should be proposed in the future to answer the questions regarding the biomechanical role of this tissue and how it participates to the response in other modes of loading.

\section{Identified material parameters}

Material parameters of a neo-Hookean strain energy density function have already been identified for the soft tissues of the human leg [5], [16]. In those studies, $\mathrm{C}_{10}$ was identified between $1 \mathrm{kPa}$ and $15 \mathrm{kPa}$. Here, the $C_{10}^{H}$ are between $0.5 \mathrm{kPa}$ and $2.1 \mathrm{kPa}$.

Although material properties of the fascia cruris have no significant impact on the response of the current FE model, the presence of this tissue seems to stiffen the leg, likely due to a structural effect. This may explain why the identified values of $C_{10}^{H}$

Due to the large deformations of the leg during localized compression, the neo-Hookean strain energy density function appeared limited since it could not capture the non-linear behavior observed experimentally (Figure $7-A$ ). However, a $2^{\text {nd }}$ order reduced polynomial equation described well the behavior of deep soft tissues of the leg (Figure 7 $-B)$.

In this bi-dimensional FE model, muscular tissues were considered as transversally isotropic, which is fairly common when assuming muscular fibers to be distributed perpendicular to the transversal plane. In the future, it would be interesting to investigate 
1 localized compression in several directions to study the anisotropic behavior of muscular 2 tissue.

3 Also, the identified mechanical properties here were those of a relaxed muscular state.

4 Other investigations with a controlled muscular contraction would allow identifying the

5 mechanical properties at an active muscular state.

6 Finally, this methodology applied to a larger population could shed a light on inter7 subject variability.

\section{Conclusion}

This paper presented a fast and non-invasive novel methodology to identify the mechanical properties of deep soft tissues of the human leg, using conventional

12 ultrasound imaging and a simple mechanical test.

13 To do so, an inverse method was used, combining a subject-specific bi-dimensional FE

14 model with localized compression tests. After the evaluation of this method on one 15 healthy subject, it was performed on three other subjects to identify the material 16 parameters of two constitutive equations of the deep soft tissues. The methodology 17 takes into account the non-linear behavior of deep soft tissues by identifying the material 18 properties on a large range of deformations rather than comparing two states (i.e. initial 19 and final). This study showed that a $2^{\text {nd }}$ order reduced polynomial strain energy density 20 function should be used over a neo-Hookean model for deep soft tissues of the leg. 21 Also, the differentiation of materials (i.e. skin, fat, fascia cruris, and muscle) allowed 22 separating the contributions of each tissue. It is the first time that a thorough analysis is 23 conducted to really separate the contribution of deep and superficial tissues in the 24 response to compression tests and this permitted to estimate the passive material 25 properties of deep soft tissues for four subjects independently of the response of their 26 other tissues.

27 
[1] E. N. Marieb, Anatomie et physiologie humaine, ERPI paris. Saint-Laurent (Québec): Pearson, 2010.

[2] N. C. Floury, N. Guignon, and A. Pinteau, Données sociales 1996: la société française, INSEE. Paris, 1996.

[3] H. Partsch, "Chapter 10 - Mechanism and effects of compression therapy," in The Vein Book, Burlington: Academic Press, 2007, pp. 103-109.

[4] S. Avril, L. Bouten, L. Dubuis, S. Drapier, and J.-F. Pouget, "Mixed experimental and numerical approach for characterizing the biomechanical response of the human leg under elastic compression," J Biomech Eng, vol. 132, no. 3, p. 31006, 2010.

11

12

13

[5] L. Dubuis, S. Avril, J. Debayle, and P. Badel, "Identification of the material parameters of soft tissues in the compressed leg," Comput Methods Biomech Biomed Engin, vol. 15, no. 1, pp. 3-11, 2012.

[6] C. P.-Y. Rohan, P. Badel, B. Lun, D. Rastel, and S. Avril, "Biomechanical response of varicose veins to elastic compression: a numerical study," J Biomech, vol. 46, no. 3, pp. 599-603, 2013.

[7] Y. Wang, S. Downie, N. Wood, D. Firmin, and X. Y. Xu, "Finite element analysis of the deformation of deep veins in the lower limb under external compression," Med Eng Phys, vol. 35, no. 4, pp. 515-523, 2013.

[8] Y. C. Fung, "Biomechanics: mechanical properties of living tissues.," N. Y. NY, 1993.

[9] M. Ottenio, D. Tran, A. N. Annaidh, M. D. Gilchrist, and K. Bruyère, "Strain rate and anisotropy effects on the tensile failure characteristics of human skin," J. Mech. Behav. Biomed. Mater., vol. 41, pp. 241-250, 2015.

[10] J. Bercoff, M. Tanter, and M. Fink, "Supersonic shear imaging: a new technique for soft tissue elasticity mapping," IEEE Trans. Ultrason. Ferroelectr. Freq. Control, vol. 51, no. 4, pp. 396-409, 2004.

[11] S. F. Bensamoun, L. Wang, L. Robert, F. Charleux, J.-P. Latrive, and M.-C. Ho Ba Tho, "Measurement of liver stiffness with two imaging techniques: magnetic resonance elastography and ultrasound elastometry," J Magn Reson Imaging, vol. 28, no. 5, pp. 1287-1292, 2008.

[12] A. Franquet, S. Avril, R. Le Riche, and P. Badel, "Identification of heterogeneous elastic properties in stenosed arteries: a numerical plane strain study," Comput. Methods Biomech. Biomed. Engin., vol. 15, no. 1, pp. 49-58, 2012.

[13] K. Miller, K. Chinzei, G. Orssengo, and P. Bednarz, "Mechanical properties of brain tissue in-vivo: experiment and computer simulation," J. Biomech., vol. 33, no. 11, pp. 1369-1376, 2000.

[14] G. Boyer, J. Molimard, M. Ben Tkaya, H. Zahouani, M. Pericoi, and S. Avril, "Assessment of the in-plane biomechanical properties of human skin using a finite element model updating approach combined with an optical full-field measurement on a new tensile device," J. Mech. Behav. Biomed. Mater., vol. 27, pp. 273-282, Nov. 2013.

[15] J. T. livarinen, R. K. Korhonen, P. Julkunen, and J. S. Jurvelin, "Experimental and computational analysis of soft tissue stiffness in forearm using a manual indentation device," Med. Eng. Phys., vol. 33, no. 10, pp. 1245-1253, 2011. 
[16] L. Bouten, "Identification des propriétés mécaniques des tissus constitutifs du mollet pour l'étude mécanique de la contention," Ecole Nationale Supérieure des Mines de Saint-Etienne, 2009.

[17] J.-S. Affagard, P. Feissel, and S. F. Bensamoun, "Identification of hyperelastic properties of passive thigh muscle under compression with an inverse method from a displacement field measurement," J. Biomech., vol. 48, no. 15, pp. 4081-4086, Nov. 2015.

[18] F. Chassagne, F. Martin, P. Badel, R. Convert, P. Giraux, and J. Molimard, "Experimental Investigation of Pressure Applied on the Lower Leg by Elastic Compression Bandage," Ann. Biomed. Eng., vol. 43, no. 12, pp. 2967-2977, 2015.

[19] F. Frauziols, J. Molimard, L. Navarro, P. Badel, M. Viallon, R. Testa, and S. Avril, "Prediction of the biomechanical effects of compression therapy by finite element modeling and ultrasound elastography," IEEE Trans. Biomed. Eng., vol. 62, no. 4, pp. 1011-1019, Apr. 2015.

[20] F. Frauziols, J. Molimard, L. Navarro, P. Badel, M. Viallon, R. Testa, and S. Avril, "Prediction of the biomechanical effects of compression therapy by finite element modeling and ultrasound elastography," 2014.

[21] C. Stecco, P. G. Pavan, A. Porzionato, V. Macchi, L. Lancerotto, E. L. Carniel, A. N. Natali, and R. De Caro, "Mechanics of crural fascia: from anatomy to constitutive modelling," Surg. Radiol. Anat., vol. 31, no. 7, pp. 523-529, 2009.

[22] K. Hibbit, "ABAQUS Theory and User Manuals Version 6.9," USA ABAQUS Inc, 2009.

[23] W. Tinsson, Plans d'expérience: constructions et analyses statistiques, vol. 67. Springer Science \& Business Media, 2010.

[24] W. M. Vannah and D. S. Childress, "Indentor tests and finite element modeling of bulk muscular tissue in vivo," J. Rehabil. Res. Dev., vol. 33, pp. 239-252, 1996.

[25] D. M. Sengeh, K. M. Moerman, A. Petron, and H. Herr, "Multi-Material 3-D Viscoelastic Model of a Transtibial Residuum from In-vivo Indentation and MRI Data," J. Mech. Behav. Biomed. Mater., vol. 59, pp. 379-392, Jun. 2016.

[26] D. Bergqvist, "New Ways to Prevent Venous Thromboembolism: The Factor Xa Inhibitor Fondaparinux and the Thrombin Inhibitor Ximelagatran," in The Vein Book, Elsevier, 2007, pp. 347-351.

[27] N. J. Papadopoulos, M. F. Sherif, and E. N. Albert, "A fascial canal for the great saphenous vein: gross and microanatomical observations.," J. Anat., vol. 132, no. Pt 3, pp. 321-9, May 1981.

[28] H. Braus and C. Elze, Anatomie des menschen: ein lehrbuch für studierende und ärzte..., vol. 1. J. Springer, 1921.

[29] A. Gefen, "The in vivo elastic properties of the plantar fascia during the contact phase of walking," Foot Ankle Int., vol. 24, no. 3, pp. 238-244, 2003.

40 
2 Figure 1: Anatomy of the human leg - Cross-section of the human right leg. The 3 fascia cruris makes a separation between the superficial tissues, composed by 4 the adipose tissue, the skin and the superficial veins, and the deep tissues, 5 composed by the muscular compartments and the deep veins. Adapted from [28].

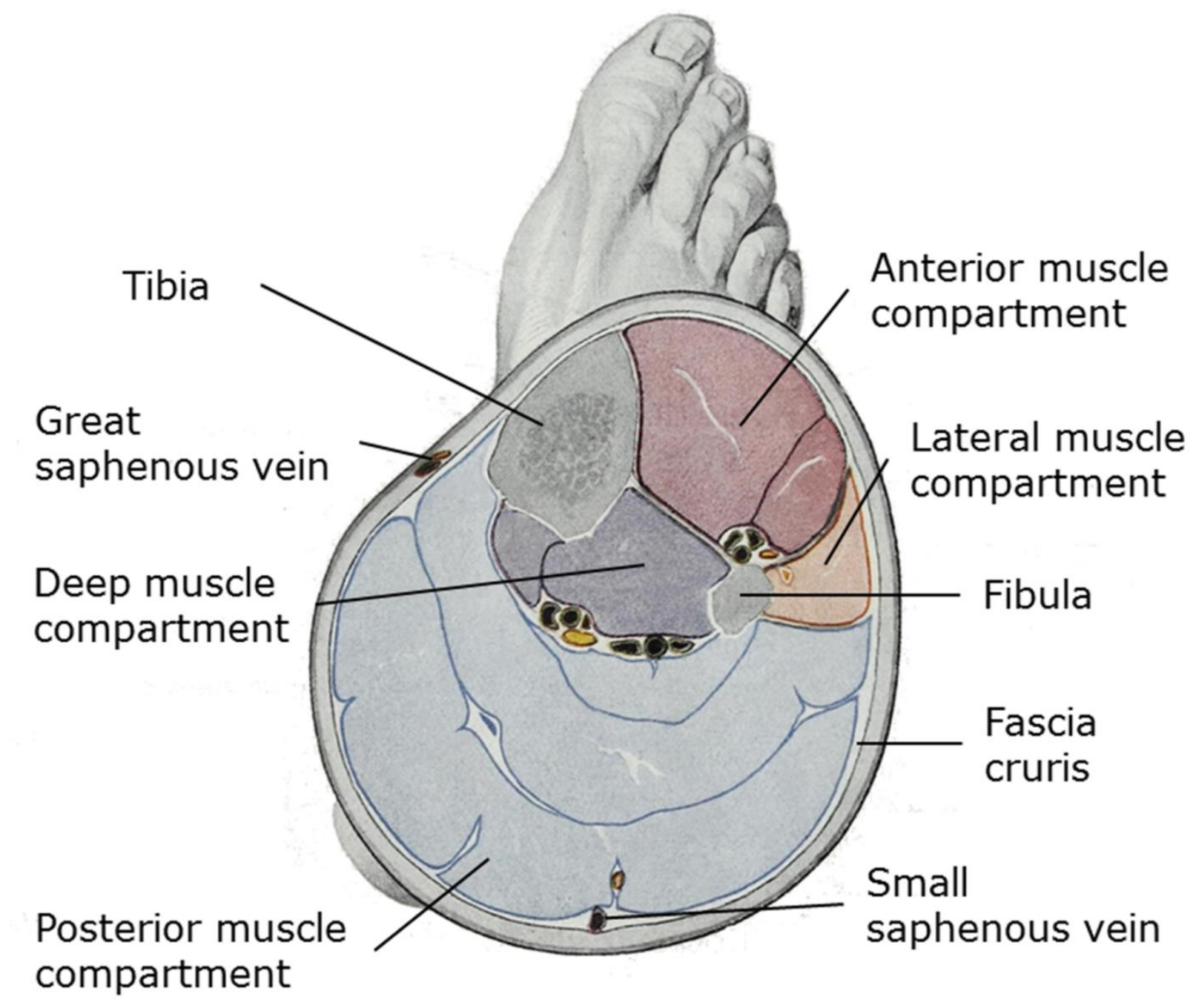


1 Figure 2 - Finite element (FE) model implementation - B-mode ultrasound 2 reconstruction of the leg (A), MRI of the leg (B), bi-dimensional FE model (C) 3 composed by the bones (tibia and fibula); the deep soft-tissue compartment, the 4 superficial soft-tissues compartment and the fascia cruris separating them. 5 6
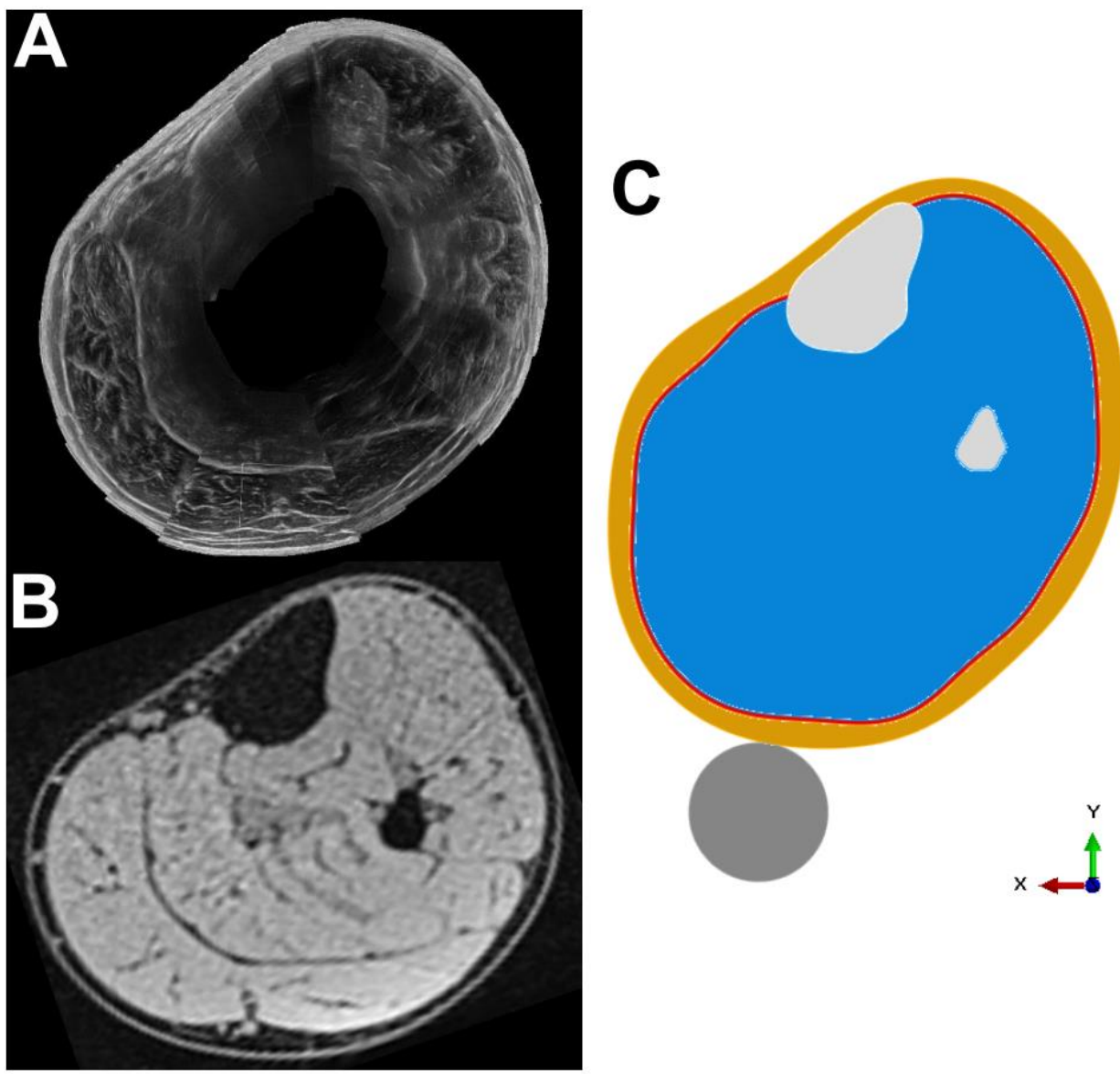
1 Figure 3 - Experimental setup - The subject is seated on a chair. The straps 2 around the foot and the rubber buffers behind the knee lead to minimum motion 3 of the leg during data acquisition. A $30 \mathrm{~mm}$ diameter cylinder is applied parallelly 4 to the leg axis. A force sensor and a displacement sensor record the desired data. 5 6




1 Figure 4 - A -Computations of an idealized leg under a localized compression 2 using a $30 \mathrm{~mm}$ diameter cylinder of different lengths. 1: 3 dimensional simulation; 3 2: bi-dimensional simulation. B - Pressure distribution applied onto the leg by the 4 cylinder. C - Function defined by Equation 3 to compensate the underestimation 5 of the reaction forces made with a 2D plane-strain model. 6
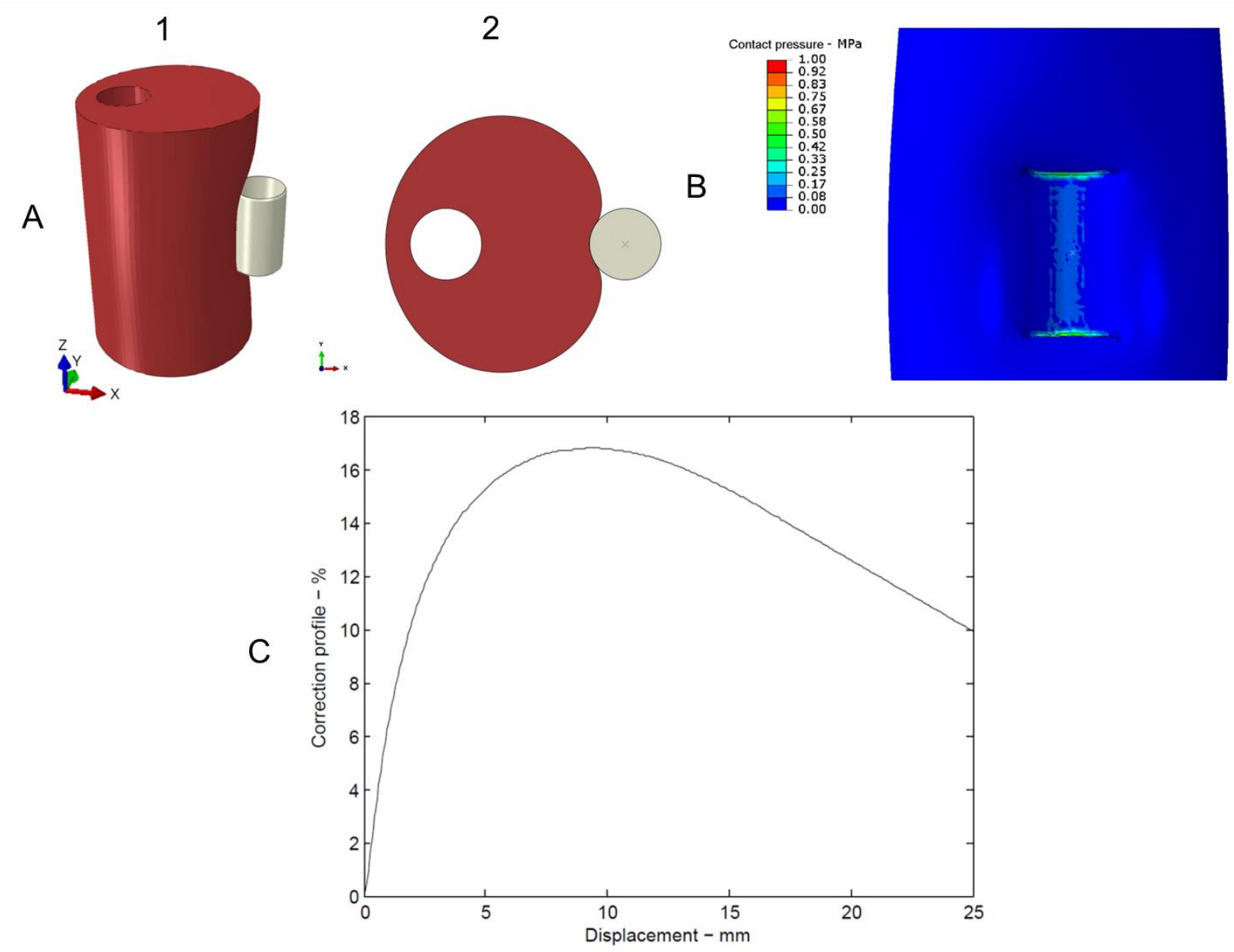
1 Figure 5 - Illustration of a force/displacement curve (A) - Sensitivities $-2^{\text {nd }}$ order 2 polynomial coefficients adjusted on the model for the mean curvature response 3 (B) and mean slope response (C) on the 3 stages of the force/displacement curve. 4 From left to right: $\mathbf{C}_{10}$ superfical soft tissues, $\mathbf{C}_{10}$ Deep soft tissues, $\mathbf{C}_{20}$ Deep soft tissues, $\mathbf{C}_{10}{ }^{\text {Fascia cruris }}$, 5 Thickness ${ }^{\text {Fascia cruris. }}$ s stands for significance. 

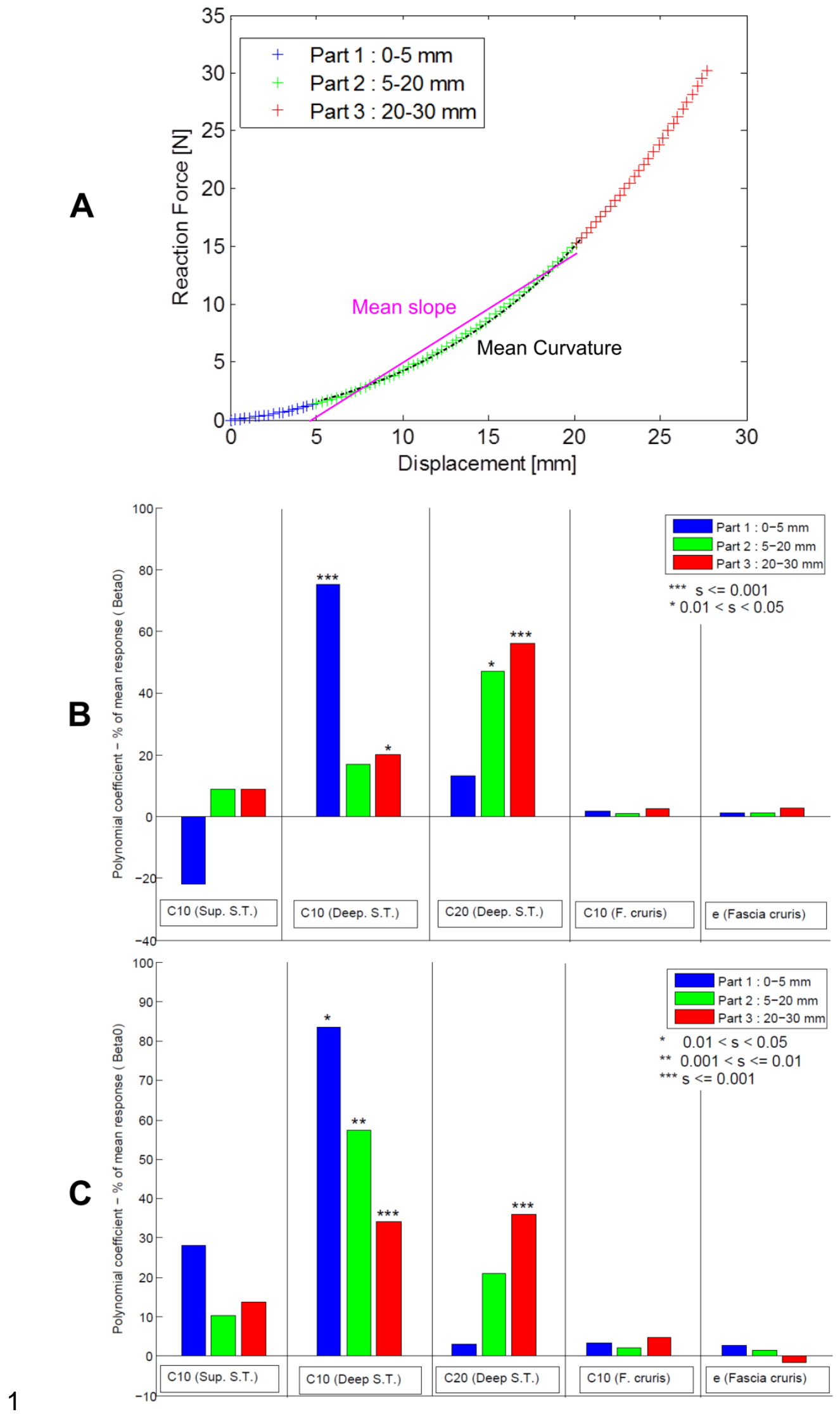
1 Figure 6 - Experimental data - Response of 4 subjects to a localized compression 2 of $25 \mathrm{~mm}$ depth with a $\mathbf{3 0} \mathrm{mm}$ diameter cylinder.

3

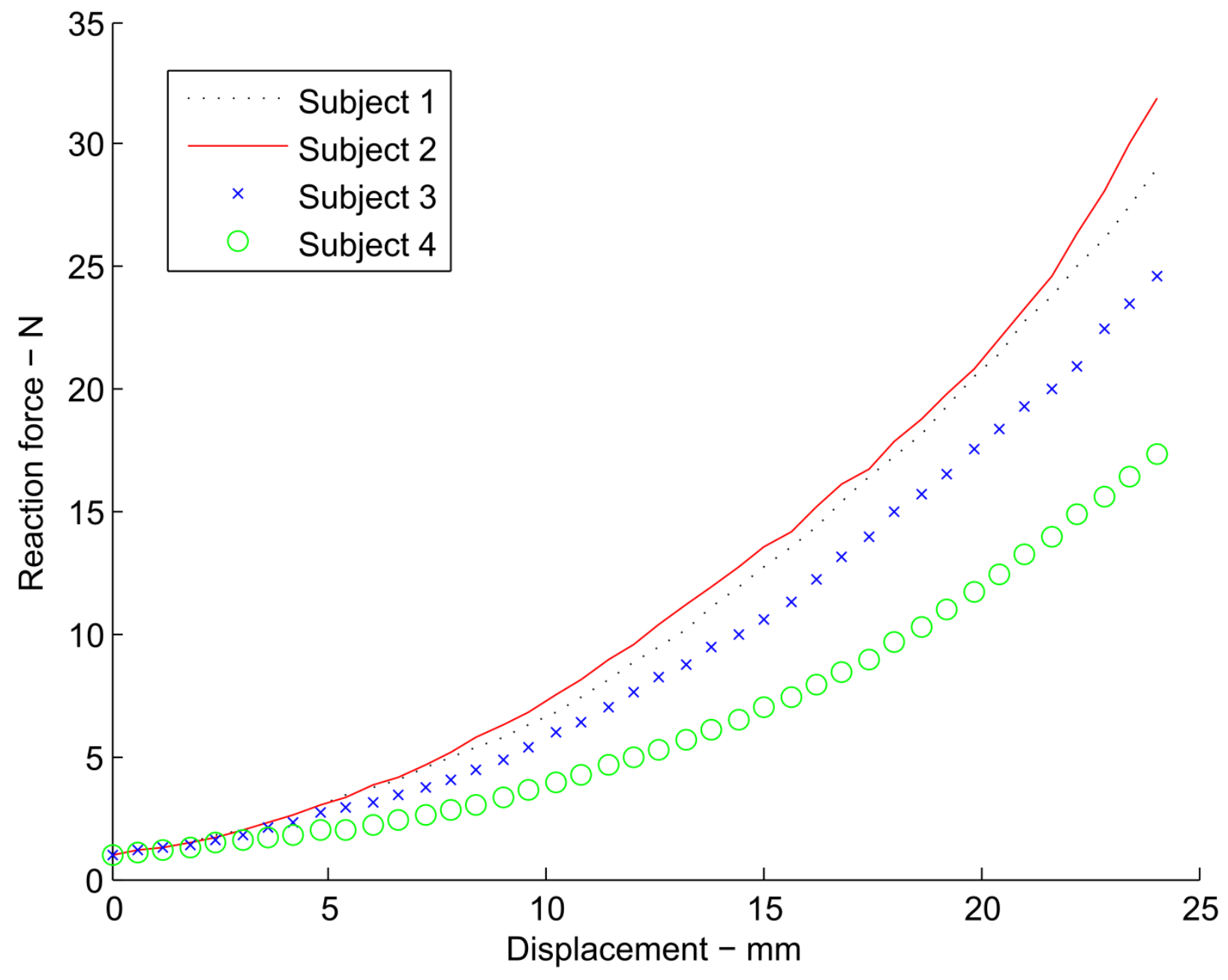


1 Figure 7 - Numerical (solid line) and experimental (dash line) force/displacement 2 curves for one subject. A - Result with the neo-Hookean constitutive equation. B

3 - Result of the 2 nd order reduced polynomial constitutive equation.
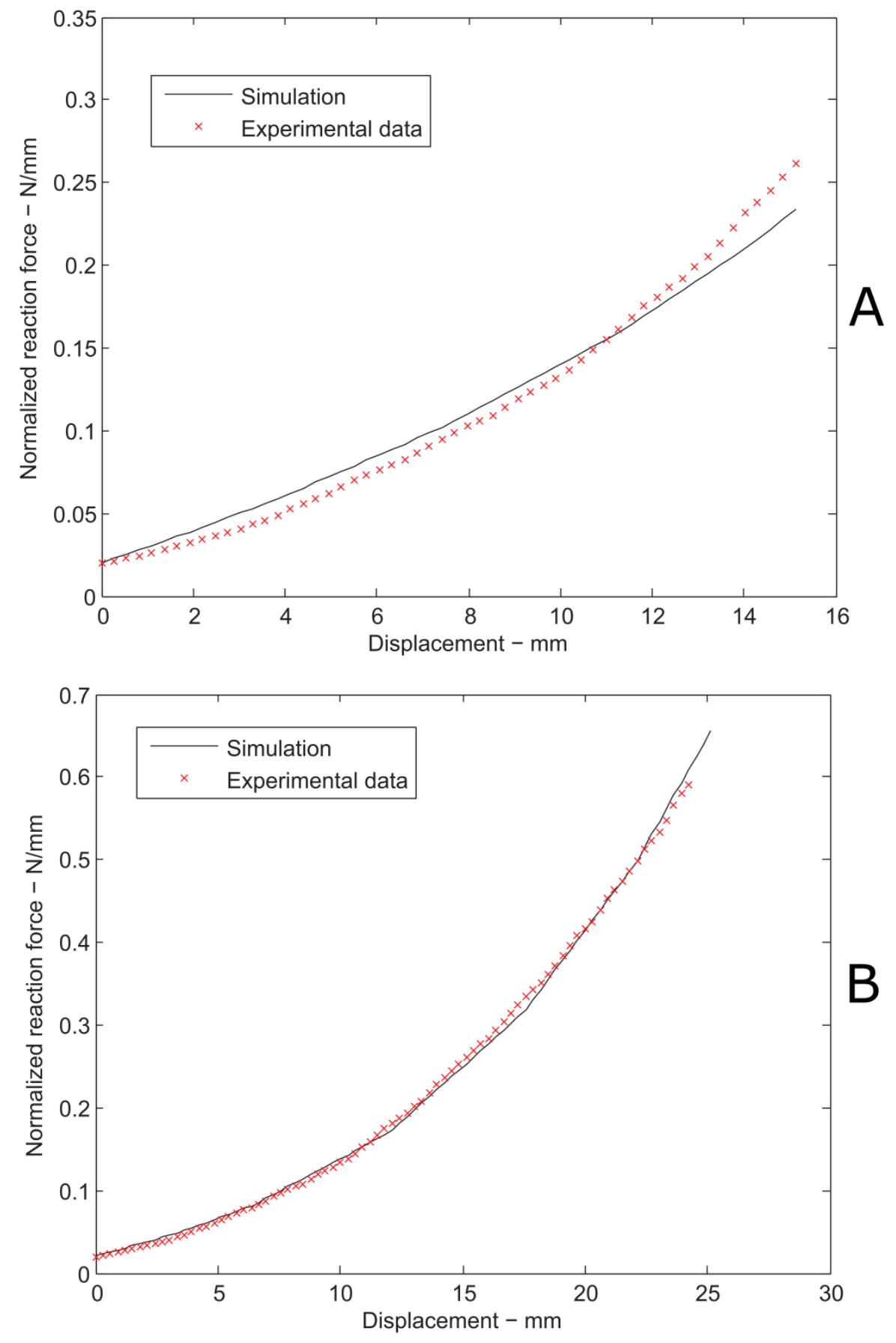


\begin{tabular}{|l|l|l|l|}
\hline Material & Behavior law & Parameters & Source \\
\hline \multirow{4}{*}{ Deep soft tissues } & $\begin{array}{l}\text { Hyper-elastic } \\
\text { neo-Hookean }\end{array}$ & $\begin{array}{l}\mathrm{C}_{10} \\
\mathrm{D}_{1}=28 \mathrm{MPa}^{-1}\end{array}$ & $\begin{array}{l}\text { Identified } \\
{[16]}\end{array}$ \\
\cline { 2 - 4 } & $\begin{array}{l}\text { Hyper-elastic } \\
\text { reduced } \\
\text { polynomial }\end{array}$ & $\begin{array}{l}\mathrm{C}_{10}, \mathrm{C}_{20} \\
\mathrm{D}_{1}, \mathrm{D}_{2}=28 \mathrm{MPa}^{-1}\end{array}$ & $\begin{array}{l}\text { Identified } \\
{[16]}\end{array}$ \\
\hline Superficial soft tissues & Hyper-elastic & $\mathrm{C}_{10}=2 \mathrm{kPa}$ & {$[16]$} \\
& neo-Hookean & $\mathrm{D}_{1}=22.5 \mathrm{MPa}^{-1}$ & {$[16]$} \\
\hline Fascia cruris & Hyper-elastic & $\mathrm{C}_{10}=100 \mathrm{kPa}$ & {$[29]$} \\
& neo-Hookean & $\mathrm{D}_{1}=22.5 \mathrm{MPa}^{-1}$ & {$[16]$} \\
\hline
\end{tabular}

1 Table 1-Material properties of the biomechanical model 


\begin{tabular}{|l|l|}
\hline Parameter & Domain \\
\hline $\mathrm{C}_{10}{ }^{\text {Deep soft tissues }}$ & From 0.5 to $30.0 \mathrm{kPa}$ \\
\hline $\mathrm{C}_{20}{ }^{\text {Deep soft tissues }}$ & From 0.5 to $30.0 \mathrm{kPa}$ \\
\hline $\mathrm{C}_{10}{ }^{\text {Superticial soft tissues }}$ & From 1.0 to $30.0 \mathrm{kPa}$ \\
\hline $\mathrm{C}_{10}{ }^{\text {Fascia cruris }}$ & From 0.1 to $10.0 \mathrm{MPa}$ \\
\hline & Thickness \\
\hline
\end{tabular}




\begin{tabular}{|c|c|c|c|c|c|}
\hline \multirow[t]{2}{*}{ Indicator } & \multicolumn{2}{|c|}{ Regression } & \multicolumn{2}{|c|}{ Error } & \multirow[t]{2}{*}{$\mathrm{R}^{2}$} \\
\hline & $\begin{array}{l}\text { Sum of } \\
\text { square }\end{array}$ & $\begin{array}{l}\text { Mean of } \\
\text { square }\end{array}$ & $\begin{array}{l}\text { Sum of } \\
\text { square }\end{array}$ & $\begin{array}{l}\text { Mean of } \\
\text { square }\end{array}$ & \\
\hline Curvature from 0 to $5 \mathrm{~mm}^{*}$ & $9.40 .10^{-5}$ & $6.3 .10^{-6}$ & $6.7 .10^{-1}$ & $4.0 .10^{-8}$ & 0.9929 \\
\hline Curvature from 5 to $20 \mathrm{~mm}^{*}$ & $3.2 .10^{-5}$ & $2.1 .10^{-6}$ & $1.2 .10^{-7}$ & $6.9 .10^{-9}$ & 0.9964 \\
\hline Curvature from 20 to $30 \mathrm{~mm}^{*}$ & $1.8 .10^{-4}$ & $1.7 .10^{-5}$ & $3.2 .10^{-1}$ & $1.9 .10^{-8}$ & 0.9982 \\
\hline Slope from 0 to $5 \mathrm{~mm}^{*}$ & $2.2 .10^{-2}$ & $1.5 .10^{-3}$ & $2.1 .10^{-4}$ & $1.2 .10^{-5}$ & 0.9907 \\
\hline Slope from 5 to $20 \mathrm{~mm}^{*}$ & $5.7 .10^{-2}$ & $3.8 .10^{-3}$ & $1.1 .10^{-4}$ & $6.7 .10^{-6}$ & 0.9980 \\
\hline Slope from 20 to $30 \mathrm{~mm}^{*}$ & 0.19 & $1.3 .10^{-2}$ & $1.4 .10^{-2}$ & $8.0 .10^{-4}$ & 0.9336 \\
\hline
\end{tabular}

Fisher's test probability: ${ }^{*} \leq 0.001$

1 Table 3 - Statistical analysis (ANOVA) of the response surface 2 


\begin{tabular}{|c|c|c|}
\hline Subject & $\begin{array}{c}\mathrm{C}_{10} \text { identified } \\
(\mathrm{kPa})\end{array}$ & $\begin{array}{l}\text { Cost function value } \\
\qquad\left(\mathrm{N}^{2}\right)\end{array}$ \\
\hline 1 & 2.11 & 0.45 \\
\hline 2 & 1.72 & 0.48 \\
\hline 3 & 1.21 & 0.23 \\
\hline 4 & 0.51 & 0.16 \\
\hline
\end{tabular}




\begin{tabular}{|c|c|c|c|}
\hline Subject & $\begin{array}{c}\mathrm{C}_{10} \text { identified } \\
(\mathrm{kPa})\end{array}$ & $\begin{array}{c}\mathrm{C}_{20} \text { identified } \\
(\mathrm{kPa})\end{array}$ & $\begin{array}{c}\text { Cost function value } \\
\left(\mathrm{N}^{2}\right)\end{array}$ \\
\hline 1 & 0.82 & 2.61 & $6.5 .10^{-3}$ \\
\hline 2 & 0.80 & 2.00 & $2.5 .10^{-2}$ \\
\hline 3 & 0.70 & 0.80 & $3.5 .10^{-1}$ \\
\hline 4 & 0.19 & 0.24 & $4.3 .10^{-1}$ \\
\hline \multicolumn{2}{|c|}{ Table 5 - Identification of $\mathbf{C}_{10}{ }^{\text {Deep soft tissues }}$ and $\mathbf{C}_{20}$ Deep soft tissues for 4 subjects }
\end{tabular}

